\title{
A multi-input UV-VIS airborne GASCOD/A4 $\pi$ spectroradiometer for the validation of satellite remote sensing measurements
}

\author{
Ivan Kostadinov $\left({ }^{1}\right)\left({ }^{3}\right)$, Giorgio Giovanelli $\left({ }^{1}\right)$, Daniele Bortoli $\left({ }^{1}\right)\left({ }^{2}\right)$, Andrea Petritoli $\left({ }^{1}\right)$, \\ Fabrizio Ravegnani $\left({ }^{1}\right)$, Giandomenico Pace $\left({ }^{4}\right)$ and Elisa Palazzi $\left({ }^{1}\right)$ \\ (') Istituto di Scienze dell'Atmosfera e del Clima (ISAC), CNR, Bologna, Italy \\ (2) Geophysics Centre of Évora - University of Évora (CGE-UE), Évora, Portugal \\ $\left(^{3}\right)$ Solar-Terrestrial Influences Laboratory (STIL), Bulgarian Academy of Science, Stara Zagora, Bulgaria \\ $\left({ }^{4}\right)$ Università degli Studi di Roma «La Sapienza», Roma, Italy
}

\begin{abstract}
The present paper describes a UV-VIS spectroradiometer named GASCOD/A4 $\pi$ developed at ISAC-CNR for remote sensing measurements aboard stratospheric M55-Geophysica aircraft, flying up to $21 \mathrm{~km}$. Obtained experimental data are used for retrieving of $\mathrm{NO}_{2}, \mathrm{O}_{3}$ and of other minor gases atmospheric content, applying the DOAS (Differential Optical Absorption Spectroscopy) method. UV actinic flux and $\mathrm{J}\left(\mathrm{NO}_{2}\right)$ are also derived. All these parameters are used for satellite data validation tasks. The specific results obtained during dedicated aircraft missions in different geographical areas have already been utilized for ENVISAT validation.
\end{abstract}

Key words UV-VIS instruments - remote-sensing actinic measurements - satellite data validation

\section{Introduction}

The current state of the Earth's climate and its future development under different scenarios has been a subject of increasing interest in the international scientific community over the last decade. Many studies, based on experimental data obtained using a large variety of instruments, indicate the existence of strong links between anthropogenic activity and a number of chemical processes taking place in the atmos-

Mailing address: Dr. Ivan Kostadinov, Istituto di Scienze dell'Atmosfera e del Clima (ISAC), CNR, Area della Ricerca CNR, Via Gobetti 101, 40129 Bologna, Italy; e-mail: I.Kostadinov@isac.cnr.it phere (IPCC, 2001). One of the major questions nowadays is to discover the critical margins of the anthropogenic impact on atmospheric parameters, beyond which climate-controlling factors become irreversible thus affecting the biosphere in an uncontrolled manner. In general, two approaches are adopted to improve knowledge in this field: a) the use of models to simulate possible scenarios and assess the impact of a large range of factors on climate; b) the collection of experimental data and the establishment of long-time data series necessary for the evaluation of ongoing climate changes. Both approaches have shortcomings. In case a), the lack of data needed for the initialization of the models can create difficulties in reproducing the observed processes, thus preventing reliable predictions. Case b) requires specific procedures for maintaining the technical characteristics of already deployed instruments. If new instruments are introduced into the monitoring net- 
works it should be guaranteed that the measurement accuracy already established in the longtime data series will not be reduced, in order to not affect the trends of the studied parameters.

The above-mentioned aspects are of particular importance regarding satellite remote sensing instruments, contributing to b). Instruments installed aboard environmental satellites, such as ODIN, ERS-1, ERS-2, ILAS, ACE, etc. supply a large variety of data, e.g., gas concentration, temperature, water vapour, cloud top height. These data are derived from measurements carried out under very different environmental conditions and observational geometries. To overcome practical problems related to b) specific intercomparisons and validation campaigns are carried out.

Satellites, with payloads dedicated to explore the Earth's atmosphere are usually launched in polar orbit to allow coverage of all geographical regions. Although the repetition rate of these satellites is of the order of a few days, groundbased measurements alone are not sufficient to fully validate satellite data. On the other hand the satellite overpass does not always coincide with the most appropriate conditions for groundbased observations. Changes in the atmosphere, due to local, regional or large-scale dynamic effects can take place during the period between two overpasses for a given location, so different air masses would be observed from the space and from the ground, leading finally to difficulties in the assessment of satellite data quality.

Ground-based instruments, distributed all over the world, as uniformly as possible, would provide an opportunity to control the satellite data capability to reproduce the actual atmospheric parameters correctly. However, there are large unpopulated geographical areas, where ground-based measurements for validation tasks cannot be performed and only balloon and aircraft measurements can provide the possibility of enlarging the validation areas. In this regard the validation campaigns of satellite remote sensors, with the participation of airborne instruments, would appear to be essential for continuing satellite payload characterization.

As a matter of fact the characterization of the scientific payload begins with the design and assembly of individual instruments and includes calibration and test procedures, carried out dur- ing the pre-flight phase. The aim of these procedures is to simulate the space conditions under which the instruments will operate in orbit. Sophisticated laboratory equipment and models are included in these pre-flight operations in order to check the behaviour of spaceborne sensors under circumstances expected in space, e.g., sharp variations in temperature (sunlight-darklight parts of the orbit), different illumination levels within instrumental Field of View (FoV), etc. Notwithstanding the efforts of scientists to reproduce space conditions in the laboratory during preflight tests, there are still factors which cannot be forecast and/or simulated correctly. For this reason it is necessary to perform specific tests after the launch to supply a complete characterization of the behaviour of the satellite instruments. The aim of the validation procedures also includes optimising methods for satellite data processing, improving the subroutines for better treatment of the observational scenarios. Some of the reasons for discrepancies between ground-based and satellite data can arise from the fact that exactly the same air masses are not observed and hence the output results will be different. In order to evaluate these differences additional information, useful for better interpretation of derived atmospheric parameters, is indispensable. Of course, part of the information can be obtained from models, but in order to adapt such models to any given scenario it is preferable to initialize them with experimental data obtained as near in the time as possible to the moment of interest.

For this reason the development of instruments, which perform simultaneous measurements within spaceborne instrumental FoVs, is considered as an advanced approach towards this end.

\section{Methods of measurements}

The first airborne version of GASCOD family instruments during the APE-1 mission in Rovaniemi, operated only in DOAS mode. Before the tropical APE-THESEO campaign (http://ape.ifac.cnr.it) the instrument was upgraded by adding two $2 \pi \mathrm{sr}$ FoV receivers for collecting of solar direct and diffuse radiation arriving at the flight level. After this modifica- 
tion the instrument became known as GAS$\mathrm{COD} / \mathrm{A} 4 \pi$ providing additional measurements necessary for a better understanding of the atmospheric photochemistry.

\subsection{DOAS mode}

GASCOD/A $4 \pi$ was initially developed as a ground-based instrument (Bonasoni et al.,1993; Evangelisti et al., 1995; Giovanelli et al., 1998), implementing the DOAS measurement technique. It relies on the retrieval of the column content of minor atmospheric gases such as $\mathrm{O}_{3}, \mathrm{NO}_{2}$, $\mathrm{BrO}, \mathrm{OClO}, \mathrm{NO}_{3}, \mathrm{SO}_{2}$, etc. from their characteristic narrow-band absorption spectra, by applying the Beer-Lambert Law in its differential form. Brewer et al. (1973) first attempted to apply this method. Since then, many authors contributed to improve the technique (e.g., Noxon, 1975; Noxon et al., 1979; Platt and Perner, 1983; Johnston and McKenzie, 1984; Solomon et al., 1987; Roscoe et al., 1994; Roscoe et al., 1996).

\subsection{Spectroradiometric mode}

Many photochemical reactions take place in the atmosphere, contributing to the variations of the local concentration of minor gases. Therefore, by knowing the incoming UV radiation flux at flight level provides an opportunity to better distinguish the role of photochemistry in overall atmospheric processes. To this end, GASCOD/A $4 \pi$ can also operate as a spectroradiometer and supply spectrally resolved upwelling and down-welling radiance (Kostadinov et al., 1999). The channels with $2 \pi \mathrm{sr} F o \mathrm{~V}$ used for this purpose are calibrated in absolute terms allowing to convert measured spectral radiation through these channels into photon flux.

\section{Instrumental design}

Space restrictions aboard M55-Geophysica aircraft and requirements for spectrometric instruments have been taken into account and GASCOD/A $4 \pi$ has been designed as a two-unit device. It includes an Optical Unit (OU) and an
Electronic Unit (EU). The OU is built-up as a multi-input device probing the atmosphere remotely in different directions. Such configuration provides possibility to perform additional measurements necessary for better understanding of the atmospheric photochemistry, underlying spectral reflectivity etc., widely used for improvement of the satellite data validation.

\subsection{Optical Unit}

OU consists of five optical inputs named $i_{0}, i_{1} \ldots i_{4}$. Three of them have Narrow Fields of View (NFoV) of 1.1E-5 sr and point towards the nadir $\left(i_{0}\right)$, zenith $\left(i_{2}\right)$ and, horizontally, to the left, perpendicular to the flight direction $\left(i_{4}\right)$. These three inputs are dedicated to DOAS measurements. The combination of $\left(i_{2}\right)$ and $\left(i_{4}\right)$ measurements is used to derive the so-called $\mathrm{NO}_{2}$ and $\mathrm{O}_{3}$ ACILA (Average gas Concentration Inside the Layer near the Aircraft) values (Petritoli et al., 2002). The third NFoV ( $\left.i_{0}\right)$ channel is used to evaluate the underlying spectral reflectivity, or combining with $\left(i_{2}\right)$ measurements to derive the tropospheric and stratospheric part of the total vertical column of the gases under interest. Such distinction appears a task of remote-sensing satellite measurements too, aimed to evaluate tropospheric pollution from space (Giovanelli et al., 2006).

The other two channels having $2 \pi \mathrm{sr} F o V$ are dedicated to collect diffused up-welling radiance, $\left(i_{1}\right)$ and diffuse + direct down-welling radiance $\left(i_{3}\right)$. Measured spectra through these channels are subsequently used to obtain spectrally resolved actinic flux need for calculation of photodissociation rate coefficients.

The OU consists custom-built monocromator based on a Jobin-Yvon holographic spherical grating with $N=1200$ grooves $/ \mathrm{mm}$ with blaze maximised at $320 \mathrm{~nm}$ and a focal length of $300 \mathrm{~mm}$ and entrance slit $100 \mu \mathrm{m} \times 8.0 \mathrm{~mm}$. The linear dispersion and resolution are about $2.4 \mathrm{~nm} / \mathrm{mm}$ and $0.7 \mathrm{~nm} @ 350 \mathrm{~nm}$, respectively, satisfying requirements for resolving power of DOAS type instruments. These two parameters depend upon $N$ and any factor changing $\mathrm{N}$ will affect the linear dispersion and resolution. Temperature variations appear to be the most impor- 
tant factor in this regard. It was found that if $d T \pm 0.2^{\circ} \mathrm{C}$ the changes of instrumental spectroscopic characteristics introduce negligible errors on the measured physical parameters. The maintenance of the required temperature regime is guaranteed by means of special internal insulating layer of the OU and thermo-electric cooling system.

The full spectral range $(295 \mathrm{~nm} \div 1100 \mathrm{~nm})$, which can be examined by GASCOD/A $4 \pi$ is sampled within single sub-intervals of $60 \mathrm{~nm}$. Depending upon the task of any given mission, sets of sub-intervals can be previously selected, although spectral intervals up to $460 \mathrm{~nm}$ are always examined to retrieve $\mathrm{O}_{3}, \mathrm{NO}_{2}$ and $\mathrm{BrO}$ concentration, allowing UV actinic flux measurements and hence the calculation of $\mathrm{J}\left(\mathrm{NO}_{2}\right)$ too.

\subsubsection{CCD sensor}

The sensor appears $2 \mathrm{D}(1100 \times 330$ pixels $)$ SITe CCD based on Back Illuminated technology. A Peltier cooling system ensures a constant operating temperature of $-30^{\circ} \mathrm{C} \pm 0.1^{\circ} \mathrm{C}$. The measured signal is binned into a matrix of 1092 columns and 11 rows. Even though the rows are reduced from 300 to 11, the curvature of the spectral lines still remains. Applying a «shift» procedure further improvement of the instrumental spectral resolution is achieved.

The exposure time needed to achieve sufficient $\mathrm{S} / \mathrm{N}$ ranges from 0.1-1.0s, under high sun elevation, to $15 \mathrm{~s}$ at a solar zenith angle of about $94^{\circ}$. The most appropriate exposure time which should be applied for single measurements during flight is calculated by means of an autoranging procedure included in the measurement duty cycle. However in certain situations, due to fast changes of environment conditions (e.g., broken clouds), CCD saturation can take place. In order to decrease the CCD memory effects to negligible levels wiping procedure is applied at the beginning of each measurement.

\subsubsection{Spectral and Absolute Calibration}

A small integrating sphere with diameter of $60 \mathrm{~mm}$, equipped with $\mathrm{Hg}$ and $\mathrm{QJ}$ tungsten lamps, is incorporated into OU for in-flight control of CCD performance and overall instrumental spectral characteristics and spectral calibrations. For each spectral sub-interval there are previously selected spectral lines used for correct positioning of the diffraction grating within \pm 1 pixel (wavelength equivalent $\approx 0.05 \mathrm{~nm}$ ). Shift and stretch procedures are applied during post-flight data processing to introduce the correct wavelength scale in the measured spectra.

The channels with $2 \pi$ sr FoV used for calculation of J-values are calibrated in an absolute manner. This includes specific laboratory measurements to find the relationship between instrumental output signal and measured radiation. A method, based on use of an integrating sphere has been developed for this purpose (Kostadinov et al., 1999). The advantage of this method arises from the possibility to irradiate simultaneously the whole FoV of the $2 \pi$ sr receivers as it take place during field measurements during the flights.

\subsubsection{Electronic Unit}

This is a pressurised unit installed inside the aircraft and consists of a DC/DC converter providing the power, a computer based on a PC104 motherboard, sensors for internal and external pressure and temperature controls. A driving program guards the execution of a duty measurement cycle. This includes home positioning of the diffraction grating, scanning mirror, band-pass filters wheel, CCD wiping and dark current measurements, etc.

\section{Data processing}

The acquired data from the narrow FoV horizontal channel $\left(i_{4}\right)$ are used to derive average concentration of $\mathrm{NO}_{2}$ and $\mathrm{O}_{3}$ along the instrumental optical axis at distances of about 50-70 $\mathrm{km}$ from the aircraft. This approach is actually based on DOAS methodology combined with a 2D single-scattering radiation transfer model (rtm) (Solomon et al., 1987), adapted to the specificity of the aircraft measurements (Petritoli et al., 2000). The model uses ray-tracing in a 
spherical atmosphere, with optical paths integrated over individual 1-km shells, within which the atmosphere is divided for the model calculations. The rtm has been adapted in order to evaluate the probability density function (for scattering towards the instrument) and to calculate the effective absorber optical path under off-axis measurement geometry (Slusser et al., 1996). Such an approach reveals the possibility of converting the derived slant columns detected at the aircraft altitude into corresponding ACILA values and to use them for satellite data validation.

While DOAS requires an appropriate reference spectrum, the calculation of actinic flux and subsequently deriving rate coefficients $(\mathrm{J}-$ values) of photochemical reactions strongly depends upon the accurate correction of all types of sensor noise and dark current. For this purpose two particular measurements - one with $0.0 \mathrm{~s}$ and $2.0 \mathrm{~s}$ integration times, together with previously mapped CCD pixel properties, corresponding to different integration times, allow one to extract the pure output signal generated by the incoming radiation. The signal is converted into instrumental units versus time, (i.u./s), allowing signals detected under different environmental and navigation conditions to be meaningfully compared. Next measured spectra are converted from (i.u./s) units into $(\mathrm{mW} / \mathrm{m} 2 . \mathrm{nm})$ units by applying the results from laboratory, pre-flight and post-flight calibrations. All detected spectra through the upwardsfacing and downwards-facing $2 \pi \mathrm{sr}$ FoV receivers, undergo a cubic-spline interpolation procedure, allowing to obtain equidistant time grids for all actinic measurements during a given flight. Derived actinic flux is converted into photon fluxes used for calculation of the J-values for a number of photochemical reactions. For example, using the $\mathrm{NO}_{2}$ absorption cross section (Harder et al., 1997) and recommended data for primary $\mathrm{NO}_{2}$ quantum yield (Gardner et al., 1987), we can calculate $\mathrm{J}\left(\mathrm{NO}_{2}\right)$.

\section{Satellite measurements requisites and aircraft measurements}

Over the last few decades, spatial and time resolution of satellite remote sensing measure- ments have been substantially improved. However, the resolution depends upon the type of observation - nadir or limb and ranges from a few kilometres up to hundreds of kilometres. Assuming M55-Geophysica aircraft cruise speed of $10 \mathrm{~km} / \mathrm{min}$ it means that a long time is needed to examine in situ airborne instruments air masses observed from space.

Of course in situ measurements have the advantage of providing results with high time resolution, but they are not sufficient for validation procedures, so airborne remote sensing measurements appear essential for the validation tasks. Each of these two measurement approaches has its advantages and shortcomings, and only their simultaneous deployment helps to achieve scientifically valuable information for satellite data validation (Kostadinov et al., 1999). GASCOD/ /A $4 \pi$ forms part of the remote-sensing chemical payload of the M55-Geophysica together with two FTIR instruments SAFIRE/A $\left(\mathrm{O}_{3}, \mathrm{HNO}_{3}\right.$, $\mathrm{N}_{2} \mathrm{O}$ and $\left.\mathrm{ClO}\right)$ and MIPAS-A $\left(\mathrm{O}_{3}, \mathrm{HNO}_{3}, \mathrm{~N}_{2} \mathrm{O}\right.$, $\mathrm{CH}_{4}, \mathrm{H}_{2} \mathrm{O}$ and $\mathrm{T}$ profiles), (http://ape.ifac.cnr.it/).

By means of vertical scanning to the right, perpendicular to the flight direction, both FTIR instruments probe atmospheric air masses observed from space and profiles of the aforementioned gases are retrieved. These profiles correspond to areas located at $\sim 150 \div 300 \mathrm{~km}$ away

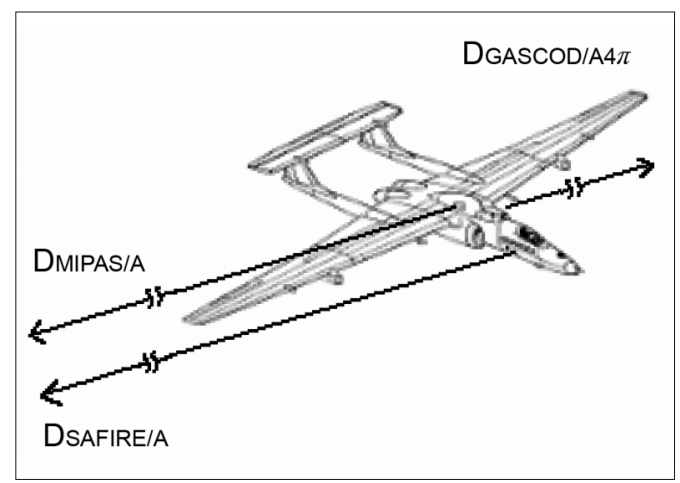

Fig. 1. Observational directions of MIPAS/A, GASCOD/A $4 \pi$ and SAFIRE /A instruments aboard M55Geophysica aircraft. Measured parameters are assigned to areas of $\sim 150 \mathrm{~km} \div 300 \mathrm{~km}$ away the aircraft (MIPAS/A and SAFIRE/A) and $\sim 50 \mathrm{~km} \div 70 \mathrm{~km}$ (GASCOD/A $4 \pi$ ). 
from the aircraft, where the strongest contributions of detected emissions arise. If we image a virtual scale defining the distances $D$, from the M55-Geophysica aircraft to the zone with maximum contribution to the retrieved parameters, fig. 1, it can be concluded that the zone lying a few tens of kilometers away from the aircraft will remain unexplored without ACILA values supplied by ASCOD/A $4 \pi$ instrument.

It took part in several validations operating successfully more than $95 \%$ of the flight time. However, the still limited quantity of available MIPAS-E and SCIAMASCHY data at the time of the preparation of this work prevent wider use of obtained by GASCOD/A $4 \pi \mathrm{NO}_{2}$ and $\mathrm{O}_{3}$ quasi in situ measurements and hence it is hard to evaluate the ability of these satellite instruments to reproduce the atmospheric content of gases under interest. Here we would like to em- phasize that before assessment of satellite data a preliminary internal quality control of the data obtained by means of different in situ and remote sensing instruments aboard M55-Geophysica be carried out (Heland et al., 2002).

We report below some examples of the results obtained by means of GASCOD/A $4 \pi$ instrument during campaigns dedicated for validation of MIPAS-E and SCIAMASCHY data.

The flight route of flight of 12 March 2003 during ENVISAT High Latitudes Campaign (http://ape.ifac.cnr.it) is shown in fig. 2, while in fig. 3 MIPAS-E $\mathrm{O}_{3}$ profile sampled within 69.3N-71.9N and GASCOD/A $4 \pi \mathrm{O}_{3}$ ACILA values are plotted. During this flight M55 aircraft flew up to $19.6 \mathrm{~km}$, so MIPAS-E data only below this altitude can be compared directly to the aircraft data. In this case satellite measurements reproduce the general shape of verti-

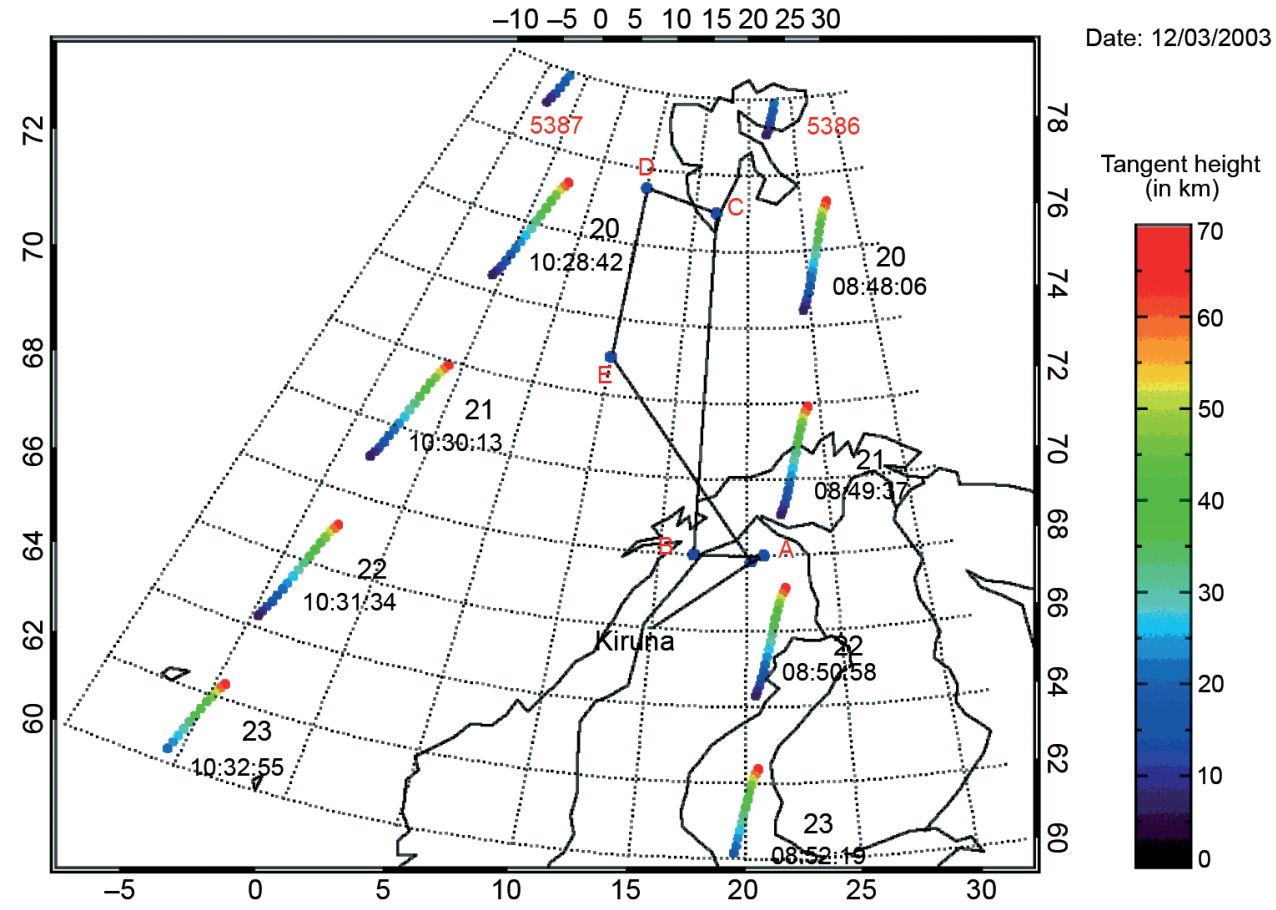

Fig. 2. M55-Geophysica aircraft flight route (12/03/2003). MIPAS-E scan 21, orbit 5386 (08:49:37UTC) is compared to GASCOD/A4 $\pi$ measurements. Closest correlation corresponds to EA back leg around $69 \mathrm{~N} \div 71 \mathrm{~N}$ (see fig. 3). Color bar indicates the tangent height of MIPAS-E line of sight. 


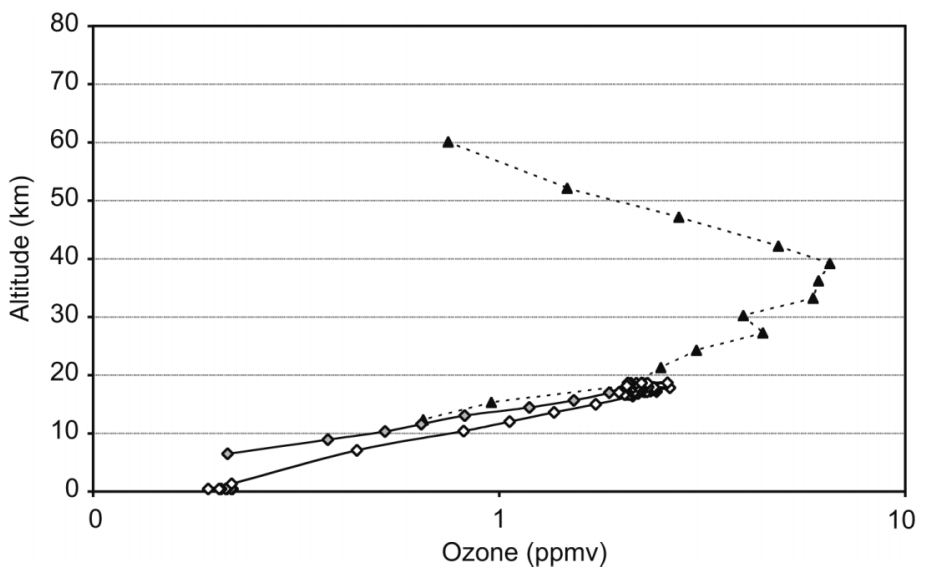

Fig. 3. Ozone mixing ratio derived in 12 March 2003 by GASCOD/A4 $\pi$ (diamonds) and MIPAS-E (black triangles) during APE-ENVISAT High-Latitude Validation Campaign. MIPAS-E profile corresponds to scan 21 taken within $69.3 \mathrm{~N} \div 71.9 \mathrm{~N}$ latitude interval. Filled diamonds correspond to EA back leg.

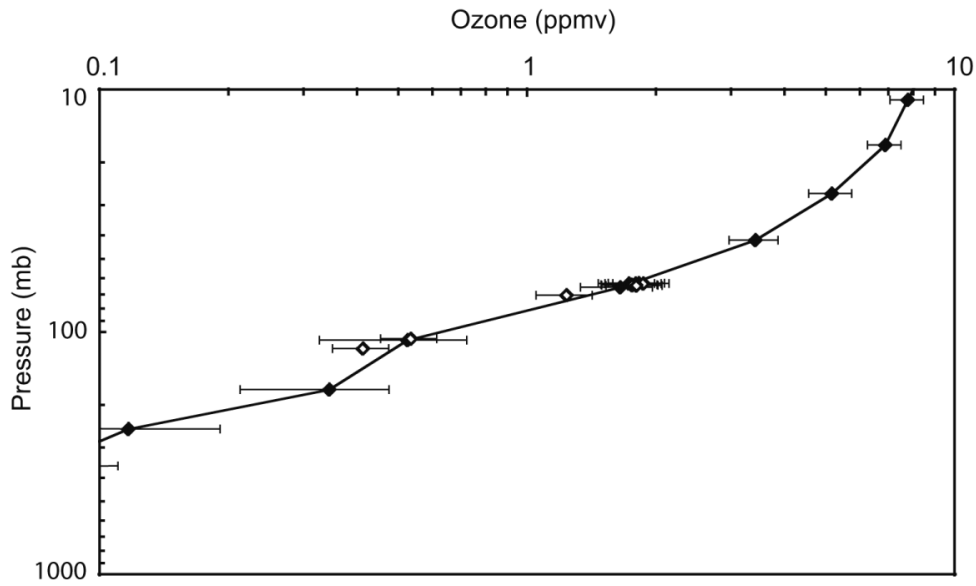

Fig. 4. Ozone mixing ratio measured by MIPAS-E (v.4.61) at 09:19:25 UTC, $\left(45.7^{\circ} \mathrm{N}, 12.9^{\circ} \mathrm{E}\right)$, error $= \pm 3 \sigma$ (black diamonds) and GASCOD/A $4 \pi$ (open diamonds) around $\left(45.2^{\circ} \mathrm{N}, 10.2 \mathrm{E}\right)$ zone. Data are obtained during APE-ENVISAT Mid-Latitude Campaign held at Forlì airport, flight 22 July 2003.

cal distribution of $\mathrm{O}_{3}$ mixing ratio obtained by GASCOD/A $4 \pi$. An overall reasonable coincidence between satellite and aircraft data sets is evident in this example. In general, the discrepancies of the results are due mainly to differences in time and spatial probing from both platforms. Better consistency is evident for the data (filled diamonds in fig. 3) corresponding to the descent of M55 aircraft, when GASCOD/ /A $4 \pi$ probe almost the same area examined approximately two hours before by MIPAS-E.

A similar comparison regarding results obtained during APE-ENVISAT Mid-Latitude Campaign are shown in fig. 4. Here only the low- 


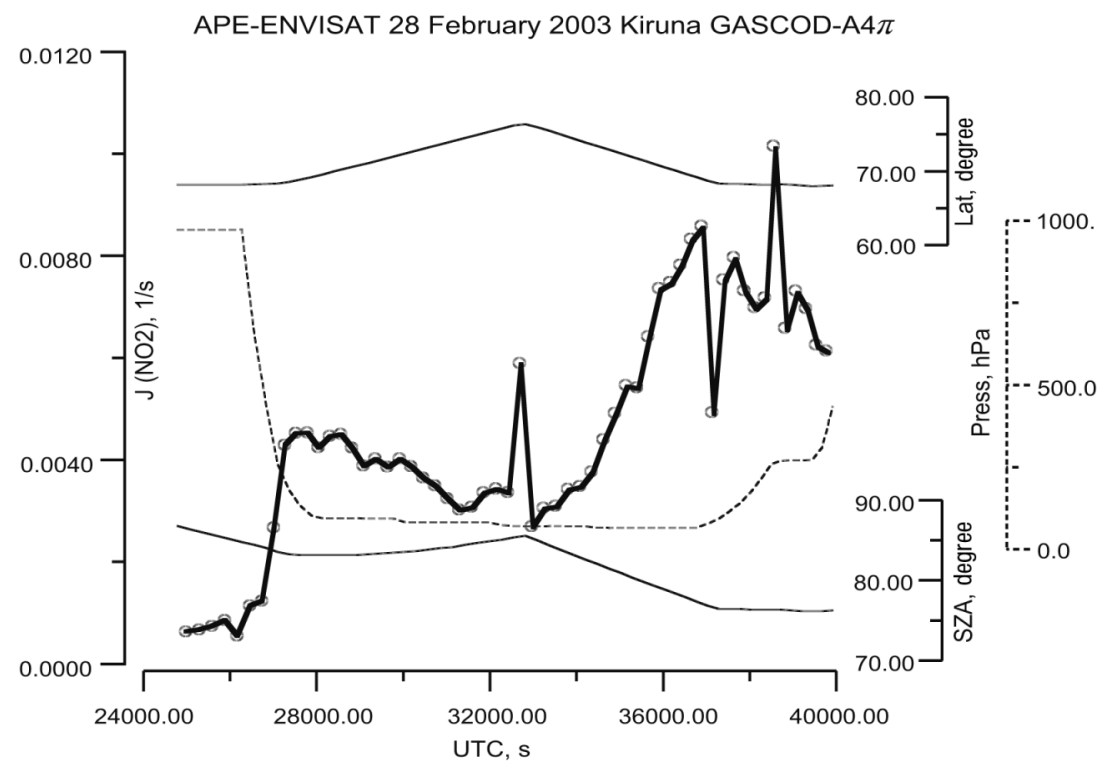

Fig. 5. $\mathrm{J}\left(\mathrm{NO}_{2}\right)$ values (open circles) measured during flight of 28 February 2003 as a function of time, solar zenith angle, latitude and pressure.

ABLE background noise versus GASCOD nadir narrow FoV

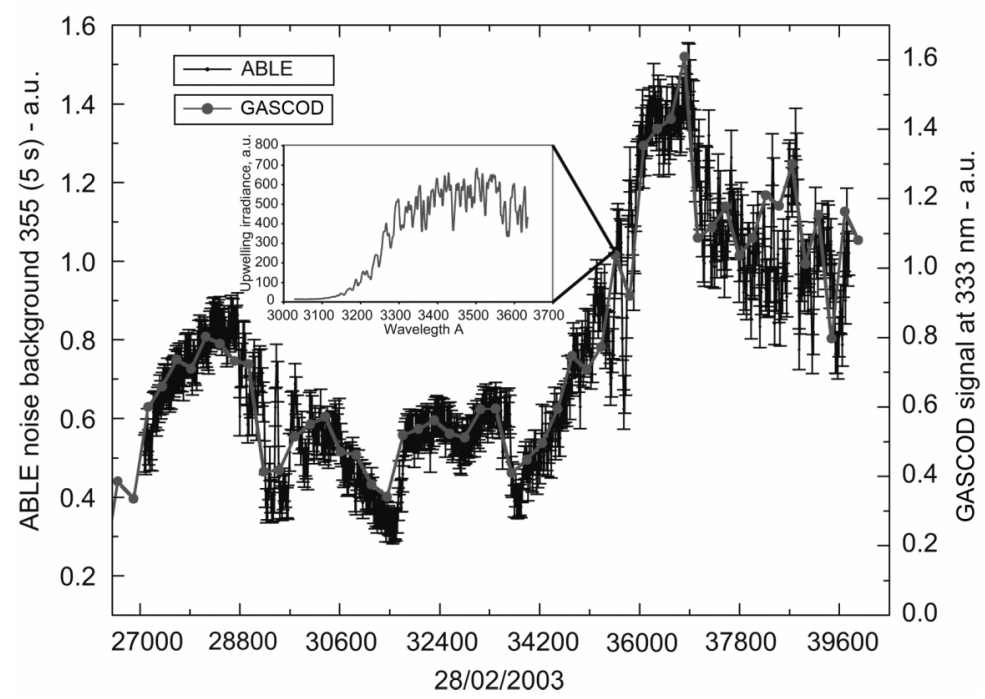

Fig. 6. ABLE narid background signal @ $355 \mathrm{~nm}$ and GASCOD/A $4 \pi$ signal in $333 \mathrm{~nm} \pm 30 \mathrm{~nm}$ spectral band obtained through nadir faced NFoV channel during 28/02/2003 flight from Kiruna within APE-ENVISAT HighLatitude Validation campaign. Due to lower time resolution of GASCOD/A4 $\pi$ some fine spatial structures of the underlying reflectivity are omitted. However for each GASCOD/A $4 \pi$ point detailed spectral properties of the scattering or reflecting objects under the aircraft is available. The axes of the nested figure represent up-welling radiance: abscise - wanelength, $\AA$; ordinate - normalised instrumental signal, a.u./s. 
er part of the $\mathrm{O}_{3}$ profile measured by MIPAS-E, corresponding to GASCOD/A $4 \pi$ measurements around $\left(45.7^{\circ} \mathrm{N}, 12.9^{\circ} \mathrm{E}\right)$ is presented. The better spatial-time coincidence of the aircraft and satellite measurements in this case leads to a closer consistency of the retrieved ozone mixing ratio by means of both instruments. Despite this, the complete understanding and quantification of satellite measurements need additional 3D CTM modelling, (Giovanelli et al., 2003) in order to account also for the transport and chemical transformation of the species under interest. This approach is applied by Wetzel et al. (2004) using KASIMA 3D CTM model output for assessment of MIPAE-E $\mathrm{NO}_{2}$ profiles. Unfortunately at the present time it is not always possible to calculate the $\mathrm{NO}_{2}$ profile from MIPAS-E measurements down to the M55 aircraft flight level, so direct MIPAS-E and GASCOD/A $4 \pi \mathrm{NO}_{2}$ comparison is limited. For instance MIPAS-E measurements do not match air masses probed by GASCOD/ $/ \mathrm{A} 4 \pi$ in the $\left(45.4^{\circ} \mathrm{N}, 11.6^{\circ} \mathrm{E}\right)$ region during the flight in 14 October 2002. However, as pointed out in Wetzel et al. (2004), the comparison of KASIMA 3D CTM NO 2 profile with GASCOD/ /A $4 \pi \mathrm{NO}_{2}$ ACILA values is qualitatively reasonable. This and another comparisons allow us to state that GASCOD/A $4 \pi \mathrm{NO}_{2}$ and $\mathrm{O}_{3}$ quasi in situ products (ACILA) can be widely deployed for further validation analysis.

It was mentioned above that GASCOD/A $4 \pi$ provides other kinds of products appearing important for atmospheric studies. Figure 5 demonstrates the variation of $\mathrm{J}\left(\mathrm{NO}_{2}\right)$ detected through the $2 \pi$ sr FoV receivers during the flight of 28/02/2003 in the APE-ENVISAT campaign, at Kiruna, Sweden. The three sharp spikes are due to the partial saturation of the measured spectra. Strong increasing of $\mathrm{J}\left(\mathrm{NO}_{2}\right)$ during the return leg of the flight is caused by increasing available solar radiation as the SZA decreases. These measurements, together with NO measurements performed by means of the SIOUX instrument (Ziereis et al., 2000) aboard the same aircraft, have been used to calculate the $\mathrm{NO}_{2} \backslash \mathrm{NO}$ ratio (Kostdinov et al., 2003). This ratio is one of the controlled parameters during adaptation of the models to the environmental conditions under which dedicated validation measurements have been carried out.
Another product supplied by GASCOD/A $\pi$ instrument appears to underlie spectral reflectivity. This product was derivable also before the installation of the nadir NFoV channel, but with very low spatial resolution, because it was possible only through the nadir $2 \pi$ sr channel. Adding the NFoV nadir faced channel significantly improves the spatial resolution of this kind of measurements. We examined the ability of GASCOD/A $4 \pi$ to reproduce spatial patterns of the landscape and/or cloud coverage comparing integrated measured spectra within 333 $\mathrm{nm} \pm 30 \mathrm{~nm}$ interval to the ABLE (AirBorne Lidar Experiment) (Fiocco et al., 1999; Pace et al., 2003) background noise measurements@355 $\mathrm{nm}$. The background noise measured by ABLE, towards the nadir, is actually an uncalibrated radiometric measurement of the solar radiation reflected and scattered from the surface and by the atmosphere. Figure 6 plots the data series obtained by means of both instruments during the flight of 28/02/2004, Kiruna. It is evident that overall spatial structures detected by ABLE are also reproduced by GASCOD/A $4 \pi$. The advantage of such combined measurements arises from the opportunity to obtain underlying reflectivity with high spatial and spectral resolution.

\section{Conclusions}

An airborne version of the GASCOD family instruments has been deployed during several campaigns dedicated to the study of tropical upper troposphere/lower stratosphere regions, satellite data validation and Antarctic ozone depletion studies. It operates successfully under a wide variety of environmental conditions. The ACILA values fill the gap in the spatial scale defined by the classical remote sensing and in situ instruments. Simultaneous measurements of atmospheric constituents and actinic fluxes provided by GASCOD/A $4 \pi$ reveal the possibility of evaluating the impact of photochemical reactions on tropospheric and stratospheric chemistry. Correlative analysis of GASCOD/A $4 \pi$ and ABLE enlarges LIDAR and spectroradiometric measurements for a better understanding of cloud processes, underlying reflectivity, radiative transfer and other aspects of geophysical science. 


\section{Acknowledgements}

This work was supported by ASI, ESA, PNRA and the EU APE-INFRA project. The author Daniele Bortoli was financially supported by the Subprograma Ciência e Tecnologia do $3^{\circ}$ Quadro Comunitário de Apoio. Thanks are due to Joerg Heland for providing MIPAS data and to G. Fiocco and M. Cacciani for providing ABLE data.

\section{REFERENCES}

Bonasoni, P., F. Evangelisti, G. Giovanelli and F. RavegNANI (1993): Remote sensing DOAS system for measurements of atmospheric trace gases, Phys. Med., 9, 304-307.

Brewer, A.W., C.T. McElroy and J. B. Keer (1973): Nitrogen dioxide concentration in the atmosphere, $\mathrm{Na}$ ture, 246, 129-133.

Evangelisti, F., A.Baroncelli, P. Bonasoni, G. GiovanelLi and F. RAVEgnani (1995): Differential optical absorption spectrometer for measurement of tropospheric pollutants, App. Opt., 34 (14), 2737-2744.

Fiocco, G., P.G. Calisse, M. Cacciani, S. Casadio, G. PACE and D. FuÀ (1999): ABLE: Development of an Airborne Lidar, J. Atmos. Oceanic Technol., 16, 13371344.

Gardner, E.P., P.D. Sperry and J.G. Calvert (1987): Primary quantum yelds of $\mathrm{NO}_{2}$ photodissotiation, J. Geophys. Res., 92, 6642-6652.

Giovanelli, G., P. Bonasoni, M. Cervino, F. Evangelisti and F. RAVEGNANI (1998): Ozone ground-based measurements by the GASCOD/A $4 \pi$ near-UV and visible system, in Proceedings of the Eighteenth Quadrennial Ozone Symposium, edited by R. BoJKov and G. VISCONTI, Parco Scientifico e Tecnologico d'Abruzzo, Italy, 707-711.

Giovanelli, G., G. Redaelli, A. Petritoli, D. Bortoli, I. Kostadinov and F. Ravegnani (2003): Three validation methods of SCIAMASCHY and MIPAS/E data with DOAS measurements obtained by the GASCOD/A $4 \pi$ spectrometer on board the Geophysica-M55 aircraft, in 16th ESA Symposium on Rocet and Balloon Programmes and Related Research, SP-530 ESA, p. 499.

Giovanelli, G., E. Palazzi, A. Petritoli, D. Bortoli, I. Kostadinov, F. Margelli, S. Pagnutti, M. Premuda, F. Ravegnani and G. Trivellone (2006): Perspectives of $2 \mathrm{D}$ and $3 \mathrm{D}$ mapping of atmospheric pollutants over urban areas by means of airborne DOAS spectrometers, Ann. Geophysics, 49 (1), 133-142 (this volume).

Harder, J.W., J.W. Brault, P.V. Johnston and G.H. Mount (1997): Temperature dependent $\mathrm{NO}_{2}$ cross sections at high spectral resolution, J. Geophys. Res., 102, 3861-3879.

Heland, J., H. Schlager, C. Schiller, N. Sitnikov, A. Ulanovsky, F. Ravegnani, C.M. Volk, A.Werner, A. Petritoli, I. Kostadinov, G. Giovanelli, D. Bortoli,
F. Stroh, M. von Hobe and the Geophysica-Team (2002): Validation of MIPAS on ENVISAT by in situ instruments on the M55-Geophysica, in Proceedings of the ENVISAT Validation Workshop, 9-13 December, ESRIN, Frascati, Italy.

IPCC (Intergovenmental Panel on Climate Change) (2001): Summary for Policymakers, IPCC WGI Third Assessment Report, Geneva.

Johnston, P.V. and R.L. McKenZIE (1984): Long-path absorption measurements of tropospheric $\mathrm{NO}_{2}$ in rural New Zeland, Geophys. Res. Lett., 11, 69-72.

Kostadinov, I., G. Giovanelli, F. Ravegnani, D. Bortoli, A. Petritoli, U. Bonafè, M.L. Rastello and P. Pisoni (1999): UV-VIS spectroradiometric system for actinic measurements on board of Geophyisica aircraft, in Proceedings of 8th Workshop Italian Research on Antarctic Atmosphere, edited by M. Colacino and G. Giovanelli, Italian Phys. Soc., Bologna, vol. 69, 293303.

Kostadinov, I., D. Bortoli, G. Giovanelli, J. Heland, A. Petritoli, F. Ravegnani, H. Schlager, A. Ulanovsky and V. YuZHKOV (2003): Aircraft measurements, modelled stratospheric $\left[\mathrm{NO}_{2}\right] /[\mathrm{NO}]$ ratio and photocemical steady-state approach within the frame of ENVISAT satellite data validation, in 16th ESA Symposium on Rocet and Balloon Programmes and Related Research, SP-530 ESA, p. 509.

McKenzie, R.L., P. Johnston, C.T. Mcelroy, J.B. Keer and S. Solomon (1984): Altitude distribution of stratospheric constituents from ground-based measurements at twilight, J. Geophys. Res., 96 (D8), 15,49915,511

NoxON, J.F. (1975): Nitrogen dioxide in the stratosphere and troposphere measured by ground-based absorption spectroscopy, Science 189, 547-549.

Noxon, J.F., E.C. Whipple JR. and R.S. Hyde (1979): Stratospheric $\mathrm{NO}_{2}$ 1. Observational methods and behaviour at mid-latitude, J. Geophys. Res., 84, 50475065.

Pace, G., M. Cacciani, P.G. Calisse, A. Di Sarra, G. FiocCO, D. FuÀ, L. RinAldi and S. CASAdIo (2003): Observation of Polar Stratospheric Clouds with the ABLE LIDAR during the APE-POLECAT flight of January 9, 1997, J. Aerosol Sci., 34 (6), 801-814.

Petritoli, A., F. Ravegnani, G. Giovanelli, D. Bortoli, Iv. Kostadinov and A. Ulanovsky (2002): Off-axis measurements of atmopheric trace gases from an airborne UV-VIS spectroradiometer, Appl. Opt., 41 (27), 5593-5599.

Platt, U. and D. Perner (1983): Measurements of atmospheric trace gases by long path differential UV/visible absorption spectroscopy, in Optical and Laser Remote Sensing, edited by D.A. KILLINGER and A. MoORADIEN (Springer Verlag, New York), 95-105.

Roscoe, H.K., J.A.C. SQuires, D.J. Oldham, A. SARKissIAN, J.-P. POMMEREAU and F. GouTAIL (1994): Improvements to the accuracy of ZENITH-SKY measurements of total ozone by visible spectrometers, J. Quant. Spectrosc. Radiant. Transfer., 52 (5), 639-648.

RoscoE, H.K., D.J. FisH and R.L. JONES (1996): Interpolation errors in UV-visible spectroscopy for stratospheric sensing: implications for sensitivity, spectral resolution, and spectral range, Appl. Opt., 35, 427-432. 
SOlOMON, S., L. Schmeltekopf and R.W. SANDERS (1987): On the interpretation of zenith sky absorption measurements, J. Geophys. Res., 92, 8311-8319.

Slusser, J., K. Hammond, A. Kylling, K. Stammes, L. Perliski, A. Dahlback, D. Anderson and R. DemaJISTRE (1996): Comparison of air mass computations, $J$. Geophys. Res., 101, 9315-9321.

Wetzel, G., M. Pirre,F. Goutail, A. Bazureau, J.-P. Pommereau, A. Bracher, M. Sinnhuber, M. Weber, K. Bramstedt, B. Funke, D.Y. Wang, A. Martinez, I.
Kostadinov, T. Blumenstock, F. Hendrick, M. VAn ROOZENDAEL and M. DE MAZIÈRE (2004): MIPAS $\mathrm{NO}_{2}$ (http://envisat.esa.int/workshops/acve2/), in Second Workshop on the Atmospheric Chemistry Validation of ENVISAT (ACVE-2), Frascati, Italy.

Ziereis, H., H. Schlager, H. Fischer, C. Feigl, P. Hoor, R. MARQUARDT and V. WAGNER (2000): Aircraft measurements of tracer correlations in the Arctic subvortex region during the Polar Stratospheric Aerosol Experiment (POLSTAR), J. Geophys. Res., 105, 24305-24313. 